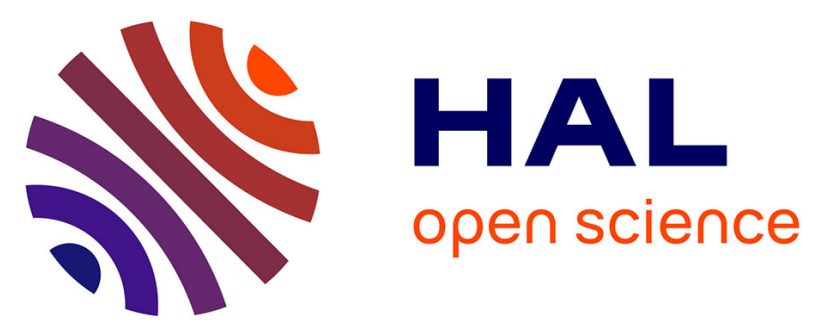

\title{
Quality Improvement of NLFM Manufacturing Process: Estimating Optimal Combination of Influencing Factor Levels
}

\author{
R. Chandima Ratnayake, M. Amarathunga
}

\section{- To cite this version:}

R. Chandima Ratnayake, M. Amarathunga. Quality Improvement of NLFM Manufacturing Process: Estimating Optimal Combination of Influencing Factor Levels. IFIP International Conference on Advances in Production Management Systems (APMS), Sep 2014, Ajaccio, France. pp.11-18, 10.1007/978-3-662-44733-8_2 . hal-01387140

\section{HAL Id: hal-01387140 \\ https://inria.hal.science/hal-01387140}

Submitted on 25 Oct 2016

HAL is a multi-disciplinary open access archive for the deposit and dissemination of scientific research documents, whether they are published or not. The documents may come from teaching and research institutions in France or abroad, or from public or private research centers.
L'archive ouverte pluridisciplinaire HAL, est destinée au dépôt et à la diffusion de documents scientifiques de niveau recherche, publiés ou non, émanant des établissements d'enseignement et de recherche français ou étrangers, des laboratoires publics ou privés. 


\title{
Quality Improvement of NLFM Manufacturing Process: Estimating Optimal Combination of Influencing Factor Levels
}

\author{
R.M. Chandima Ratnayake ${ }^{1, *}$ and M. Amarathunga ${ }^{2}$ \\ ${ }^{1}$ Department of Mechanical and Structural Engineering and Materials Science, University of \\ Stavanger, Stavanger, Norway \\ chandima.ratnayake@uis.no \\ ${ }^{2}$ Richard Pieris Natural Foams Ltd., Biyagama, Sri Lanka
}

\begin{abstract}
Natural latex foam mattresses (NLFMs) are manufactured using the latex extracted in its purest form of milky white liquid, which is tapped from the trunks of mature rubber trees. The natural latex foam mattress manufacturing (NLFMM) process undergoes several processing stages before the natural latex is converted into an ultra cushioning material with a wide range of firmness and comfort. Among the other processing steps, the gelling process has been found to play a significant role in controlling the quality of the final product, provided that quality raw materials have been supplied to the manufacturing plant. This manuscript suggests a methodology for estimating optimal levels of parameters that affect the gelling process, focusing on minimizing the influence on mattresses' surface quality deterioration. A case study has been performed in collaboration with one of the natural latex foam manufacturing plants to recognize main quality deterioration mechanisms and corresponding process parameters using the engineering robust design approach to establish the optimal combination of influencing factor levels.
\end{abstract}

Keywords: Natural latex foam manufacturing, defects minimization, engineering robust design, quality deterioration factors

\section{Introduction}

Natural latex foam mattress manufacturing (NLFMM) starts with the latex, which is extracted in its purest form when tapped from the trunks of mature rubber trees [1]. The extracted natural latex is then converted into an ultra cushioning material with a wide range of firmness and comfort, through heat, vacuum, and freezing. In general, the NLFMM processes follow one of the following approaches [2]: 1. Standard process: this is also referred to as the Dunlop process (Note: It is a less expensive process for NLFMM whilst producing a finished product that has a steadier feel); 2. Talalay process: this is the most advanced NLFMM process which manufactures latex mattress cores (Note: Latex cores manufactured using the Talalay process have been proven to be superior in comfort and durability with a greater range of firmness, i.e. from very soft to super firm).

\footnotetext{
* Author of Correspondence
} 
Currently different kinds of categorizations are used to describe NLFMs [3]. For instance, there are three main kinds of categorizations in latex mattresses: 1. Pure latex (i.e. at least $20 \%$ natural and a blend of $80 \%$ synthetic); 2 . Natural latex (at least $80 \%$ natural and a blend of $20 \%$ synthetic); and 3. $100 \%$ natural latex (i.e. $2 \%$ forming additives, $2 \%$ soaping agents and $96 \%$ latex from rubber trees) [3]. The $100 \%$ NLFMM process has been selected for the current study. Generally, natural rubber is very soft and elastic, whilst synthetic rubber provides good hardness to the foam.

The natural rubber is very dilute when it is tapped from a tree, having a rubber content of about only $30 \%$. Hence, it is concentrated before use to above $61.5 \%$ solids which has been referred to as total solid content (TSC). Usually, $60.0 \%$ of TSC is rubber and the remaining 1.5\% are compounds that are unique to natural latex (proteins, phospholipids, carbohydrates, amino acids) [4]. The aforementioned unique ingredients play a significant role in explaining the behavior of natural latex [4].

The initial preservation of the raw natural rubber latex and later for NLFM requires sending latex through several processing stages. In this context, controlling the quality of the final product is of significant importance and challenging. In particular, minimizing surface defects requires the identification of optimum settings of influencing factors. This manuscript first illustrates the results of a preliminary study, which have been utilized for the identification of influencing factors in relation to major surface defects. Then the manuscript suggests an engineering robust design based approach and framework to carry out experiments. Finally, it presents the results of the experiment (i.e. optimal combination of influencing factors).

\section{Industrial Challenge and Preliminary Study}

\subsection{Industrial Challenge}

The surface quality of mattresses is assessed based on the size and number of defects that are allowed to appear on the surface (top, bottom and sides) of the mattresses that are graded for the export market. Ideally a product is said to be of exportable grade when the product has a very uniform surface all around with no surface depressions or holes appearing. Fig. 1 illustrates the basic process of the natural latex foam manufacturing.

However, it is difficult to achieve the desired surface finish, especially due to the fact that there are inherent limitations present in the NLFMM process and technology as well as in the process of extraction of the main raw material (i.e. being a "natural or living" product). In the context of NLFMM process product quality, apart from the latex compounding step (i.e. related to the quality of the raw materials), the gelation is the next significant step that has a greater effect on controlling surface finish. Hence, the gelling process has been a subject for study. The main focus has been on developing a methodology for estimating the variables' set points (or levels) to improve surface finish. 


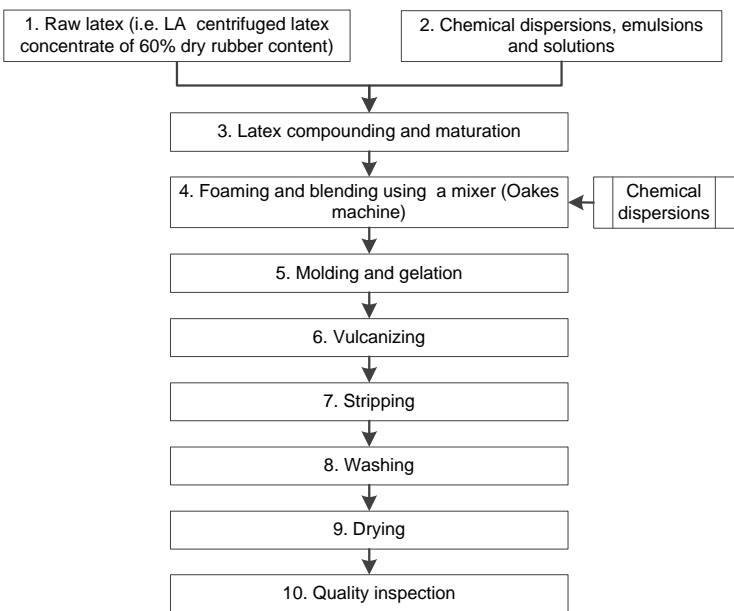

Fig. 1 The process of the natural latex foam manufacturing

\subsection{Preliminary Study}

A preliminary study has been carried out to investigate the different kinds of defects present in a natural foam latex mattress and their relationships to various influencing factors. Information has been gathered to obtain an overview about maturation time and different kinds of defects. Fig. 2 illustrates compounded latex maturation data.

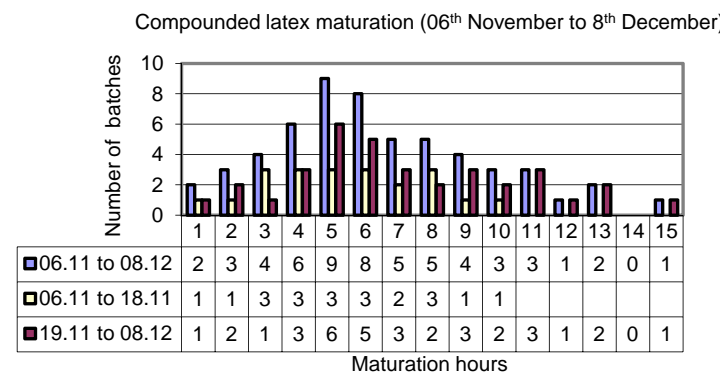

Fig. 2 Compounded latex maturation data

Fig. 3 illustrates results of preliminary defect analysis for defects size less than $5 \times 5$ $\mathrm{cm}^{2}$. Fig. 4 illustrates results of preliminary defect analysis for defects size greater than $5 \times 5 \mathrm{~cm}^{2}$. 


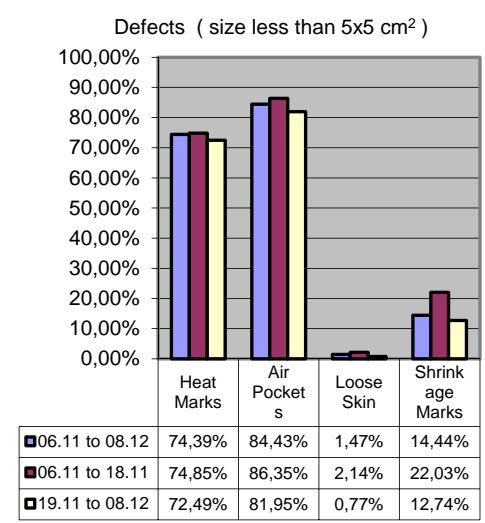

Fig. 3 Defects distribution of natural latex foam mattresses (size less than $5 \times 5$ $\left.\mathrm{cm}^{2}\right)$
Defects (size larger than $5 \times 5 \mathrm{~cm}^{2}$ )

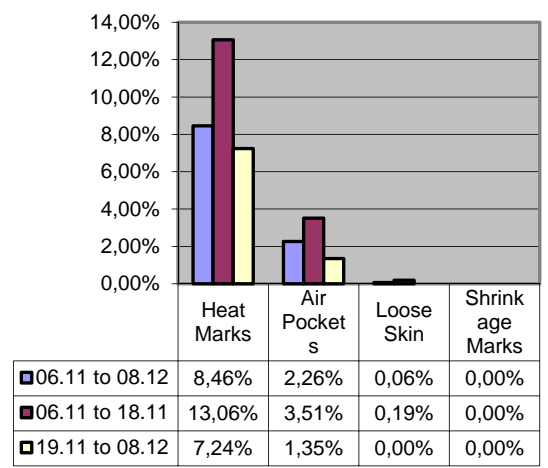

Fig. 4 Defects distribution of natural latex foam mattresses (size larger than $5 \times 5$ $\left.\mathrm{cm}^{2}\right)$

Table 1 illustrates the main surface defects vs. related codes which have been identified in a preliminary prioritization study of the surface finish.

Table 1. Main surface defects vs. related codes

\begin{tabular}{ll}
\hline Surface defect & Code \\
\hline Heat marks & 2 \\
Loose skin & 13 \\
Shrinkage marks/lake marks & 15 \\
\hline
\end{tabular}

A fish bone diagram has been developed to understand the influence of different factors' interaction with the surface finish [5]. Using a fish bone diagram, the major influencing factors that affect the surface finish of natural latex foam mattresses have been identified and are illustrated in Fig. 5.

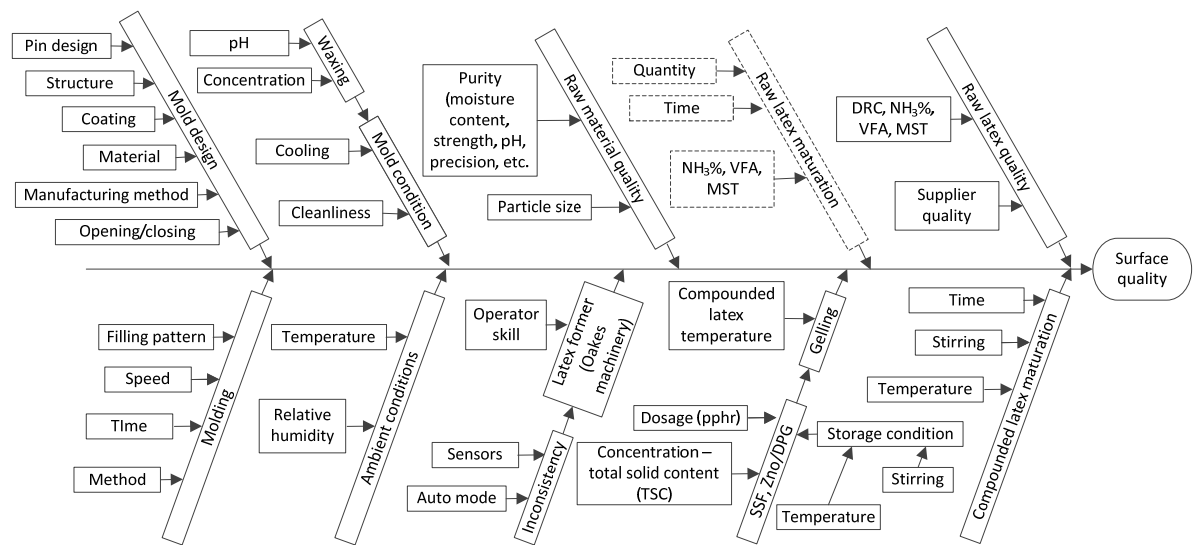

Fig. 5 Factors affecting the surface quality of natural latex foam mattresses (fish bone diagram) [Note: mechanical stability time (MST)] 
Table 2 illustrates the parameters influencing quality deterioration that have been identified from the preliminary investigation.

Table 2. Parameters influencing quality deterioration

\begin{tabular}{|c|c|c|c|c|c|}
\hline \multirow[t]{2}{*}{ Symbol } & \multirow{2}{*}{ Quality deterioration influencing factor } & \multirow{2}{*}{ Units } & \multicolumn{3}{|c|}{ Levels } \\
\hline & & & 1 & 2 & 3 \\
\hline A & Raw latex maturation & days & 30 & 37 & 44 \\
\hline $\mathrm{B}$ & Compounded latex maturation & hours & 2 & 8 & 14 \\
\hline $\mathrm{C}$ & SSF dosage & pphr & 0.9 & 1.5 & 2.2 \\
\hline $\mathrm{D}$ & $\mathrm{ZnO} / \mathrm{DPG}$ dosage & pphr & 2 & 4 & 6 \\
\hline $\mathrm{E}$ & Mold Temperature & ${ }^{0} \mathrm{C}$ & 30 & 40 & 50 \\
\hline $\mathrm{F}$ & $\mathrm{NH}_{3}$ content of latex & $\mathrm{W} / \mathrm{W} \%$ & 0.18 & 0.22 & 0.28 \\
\hline G & $\mathrm{pH}$ of PEG (mold releasing agent) & $\mathrm{pH}$ & 7 & 10.5 & 12 \\
\hline
\end{tabular}

Hence, it is vital to develop a methodology to estimate the optimal combination of quality deterioration influencing factors in order to make the necessary improvements to surface quality in terms of reducing the number and size of the surface defects that appear on manufactured latex foam mattresses.

\section{$3 \quad$ Methodology}

\subsection{Matrix Experiments using Orthogonal Arrays}

An efficient way to study the effect of several control factors simultaneously is to plan matrix experiments using orthogonal arrays which have been introduced in the engineering robust design approach (ERDA) [6,7]. A matrix experiment consists of a set of experiments which provides the possibility to change the settings of the various product or process parameters, which it is necessary to study, from one experiment to another $[8,9]$. For processes that involve many factors, experiments are conducted using special matrices called Orthogonal Arrays [10]. After conducting a matrix experiment, the data from all experiments are taken together and analyzed to determine the effects of the various parameters [7], [6].

\subsection{Analysis Approach}

The following steps are adapted from the literature applying the ERDA in designing the experiments and finding the optimal internal vibration settings which give the best surface finish [6].

- Identify the challenge: In this study, the challenge is to investigate the optimal combination of influencing factor settings which minimizes the surface defects.

- Determination of the performance characteristic(s) and the measuring system: The surface finish is evaluated by visual inspection and the use of appropriate 
measuring devices. According to the classification, the smaller the number of defects, the better the surface finishes.

- Determination of the variables (parameters) affecting the performance characteristic(s): There are various factors affecting the NLFM surface finish (see Fig. 5). Considering the case study on "surface quality improvements for latex foam mattresses", the significant process parameters have been identified as: Polyethylene Glycol (A), raw latex maturation (B), compounded latex maturation (C), SSF (D), ZnO/DPG (E), mold temperature (F), ammonia content of latex (G) (see Table 2).

- Determination of the number of levels and values of the controllable variables (parameters): In this case, only the controllable parameters are discussed. For example, Table 4 gives three levels for the variable raw latex maturation time (i.e. 30, 37 and 44 days). Only 18 experiments are needed to study the entire experimental parameters using the $L 18$ orthogonal array.

- Determination of loss function and the performance statistics: The "smaller-isbetter" (SMB) loss function is selected for calculating signal to noise ratios $(\mathrm{S} / \mathrm{N}$ ratios) for surface defects [11] [see Equation (1)].

$$
S / N \text { ratio }\left(\eta_{i}\right)=-10 \log _{10}\left\{\left(\frac{1}{n}\right) \sum_{i=1}^{n} \frac{1}{y_{i j}^{2}}\right\}
$$

where

$n=$ number of replications

$y_{i j}=$ performance indicator value $(i=1,2 \ldots n$ and $j=1,2,3 \ldots n)$.

- $\quad$ Conducting experiments and recording of results.

- Analyzing data and selection of the optimum value of the controllable variables.

- Verifying the results.

- $\quad$ Re-establishing and documenting the NLFMM process parameters.

Under the optimum set-points, the corresponding $\eta_{\text {opt }}$ is calculated using the additive model for factor effects (see (2) suggested by [6].

$$
S / N \text { ratio }(\eta)=\alpha+\alpha_{i}^{A}+\alpha_{j}^{B}+\alpha_{k}^{C}+\alpha_{l}^{D}+\alpha_{m}^{E}+\alpha_{n}^{F}+\varepsilon_{i j k l m n}
$$

where

$\alpha=$ overall mean $\mathrm{S} / \mathrm{N}$ ratio for surface defects count over all the possible combinations

$i, j, k, l, m . n=$ particular levels of each of the parameters which were selected (so in this model $i, j, k, l, m, n$ must all take on one of the values 1,2 or 3 )

$\boldsymbol{\alpha}_{i}^{A}=$ deviation from $\alpha$ caused by setting parameter "A" at level $i$ (similarly, other terms in Equation (2) are defined)

$\varepsilon_{i j k l m n}=$ error term.

The calculated $\eta_{o p t}$ represents the theoretical level of defect value at optimum settings found by experimentation. However, a verification experiment shall be per- 
formed to investigate the accuracy of the optimum settings. Fig. 6 provides a framework to illustrate the calculation and experimentation approach.

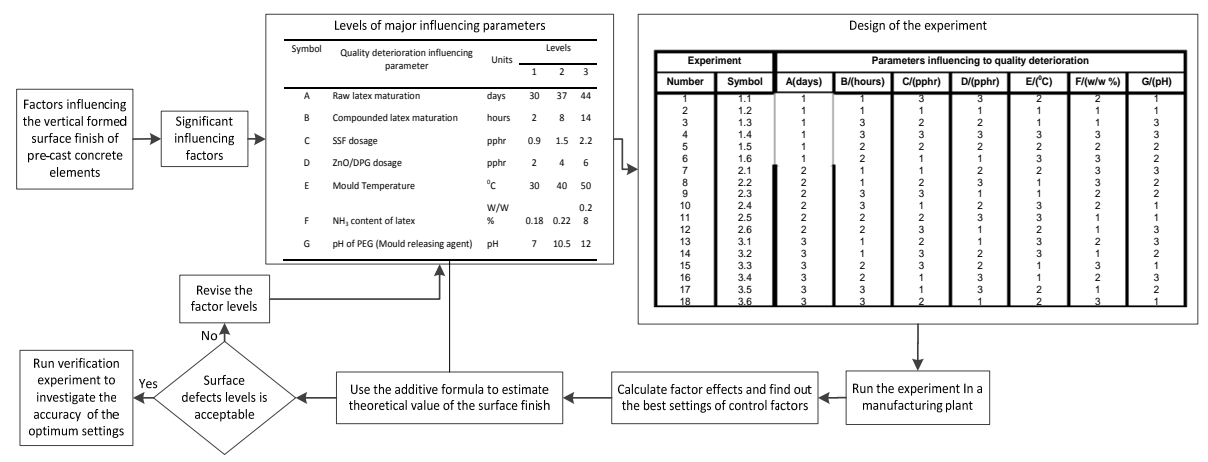

Fig. 6 Framework for experimentation, estimation of best settings and verification

\section{$4 \quad$ Results and Discussion}

The levels of the factors to minimize the affect to surface finish of NLFM have been established based on the final analysis of the matrix experiment results and further discussions with a team of expert personnel. For the raw latex maturation time, level 3 (i.e. 44 days) has been shown to be the best level. However, due to the practical limitations of having such a long maturation in the latex storage tanks, the team has decided to purchase latex with 21 days' minimum maturation and issuing it for the manufacturing process after it reaches 30 days minimum.

For the compounded latex maturation time, levels 1 and 2 have indicated more or less the same effect on the defect code numbers 2, 13 and 15. Therefore, the team decided to adopt six hours minimum (within levels 1 and 2), while the raw latex maturation is 30 days minimum. For instance, if the raw latex maturation is closer to 44 days, then the compounded latex maturation has to be closer to level 1 (i.e. two hours).

For the SSF dosage, level 1 ( $0.9 \mathrm{pphr})$ has been shown to be the optimum level to reduce defect code number 2 ; however, its performance in reducing defect code number 13 is poor. Hence, the team decided to reduce the SSF dosage by $0.1 \mathrm{pphr}$ from the present operating level.

For $\mathrm{ZnO} / \mathrm{DPG}$ dosage, level 3 (i.e. $6 \mathrm{pphr}$ ) has indicated a greater effect in reducing defect code number 13; however, on average level 2 has a similar effect in reducing other defects, as well as having a good control over maintaining other parameters. Hence, the team has decided to increase the $\mathrm{ZnO} / \mathrm{DPG}$ dosage by $0.1 \mathrm{pphr}$ as it reduces defect code number 13 .

For mold temperature, level 1 (i.e. $30{ }^{\circ} \mathrm{C}$ ) has the greatest effect in reducing defect code number 2 . For defect code number 13 , level 3 (i.e. $50{ }^{\circ} \mathrm{C}$ ) is indicated to be the best. Therefore, the team decided to adopt level 1 as the optimum level in order to reduce defect code number 2 to a greater extent. 
For $\mathrm{NH}_{3}$ content, the present operating level seems to be the best at controlling defects as well as other tested parameters. Also, for the factor pH of PEG, level 2 (10.5 $\mathrm{pH}$ ) has been proven to be the best level for most of the tested parameters.

\section{Conclusion}

This manuscript proposes the use of the optimized design of experiments approach (i.e. ERDA) to estimate the optimal combination of factors influencing NLFM surface finish. The results indicate that the suggested approach is significantly efficient and effective in establishing the optimal combination of factor settings. Hence, it is possible to use the same approach in establishing the optimal combination of other settings by careful examination of the existing NLFMM.

Further research should be carried out to address the fuzziness present among the factor levels caused by the incorporation of experts' knowledge. This would enable further refined optimal factor level combinations to be established in an effective and efficient way.

\section{References}

1. Nawamawat, K., Sakdapipanich, J.T., Ho, C.C., Ma, Y., Song, J., Vancso, J.G.: Surface Nanostructure of Hevea Brasiliensis Natural Rubber Latex Particles, Colloid. Surface. A: Physicochemical and Engineering Aspects. 390 (1-3), 157-166 (2011)

2. Jones, K.P.: CHAPTER 1 - Historical Development of the World Rubber Industry. Dev. Crop Sci. 23, 1-25 (1992)

3. Ryan, J.: Latex as a Comfort Layer. http://www.factory-beds-direct.co.uk/latex-as-acomfort-layer (2014) (accessed on 21.04.2014)

4. Sansatsadeekul, J., Sakdapipanich, J., Rojruthai, P.: Characterization of Associated Proteins and Phospholipids in Natural Rubber Latex. J. Biosci. Bioeng. 111 (6), 628-634 (2011)

5. Ratnayake, R.M.C.: Framework for Computing Machining Parameter Settings in CNC Machines: An Industrial Case Study. Int. J. Comput. Sys.Eng.. http://www.inderscience.com /info/ingeneral/ forthcoming.php?jcode=ijcsyse (2014)

6. Phadke, M.S.: Quality Engineering using Robust Design. PTR Prentice-Hall Inc., Englewood Cliffs, New Jersey (1989)

7. Ratnayake, R.M.C.: Small and Medium Enterprises Project Finance: Identifying Optimum Settings of Controllable Factors, Int. J. Appl. Decision Sci. 7 (2), 136-150 (2014)

8. Ratnayake, R.M.C., Valbo, I.: Use of Robust Design Technique in Job Shop Manufacturing: A Case Study of Die-Sinking Electro Discharge Machining. Int. J. Perform. Eng. 10 (2), 153-160 (2014)

9. Taguchi, G., Phadke, M.S.: Quality Engineering through Design Optimization. Conf. Record GLOBECOM 84 Meeting, IEEE Communications Society, Atlanta, GA, November (1984)

10. McEwan, W., Belavendram, N., Abou-Ali, M.: Taguchi Methods and Expert Systems in Fabrication Design. Int. J. Pres. Ves. Pip. 53 (1), 47-61 (1992)

11. Kamaruddin, S., Zahid Khan, A., Foong, S.H.: Application of Taguchi Method in the Optimization of Injection Moulding Parameters for Manufacturing Products from Plastic Blend. IACSIT Int. J. Eng. Tech. 2 (6), ISSN: 1793-8236 December (2010) 